\title{
当代中国政治话语中和 谐文化因子解读
}

\section{Interpretation on the Cultural \\ Factors of Harmony in \\ Contemporary Chinese Political Discourses}

刘和林*

长沙大学外国语系

长沙 湖南 中国, 410003 hlliu20081@163.com

Liu Helin

Changsha University

Department of Foreign Languages Changsha, Hunan, China 410003
当代中国政治话语建立在中国文化价值基 础之上, 通过 “以人为本”、“和而不同”、“德 法和谐”、“中国梦” 等和谐话语体现出来。 本研究力图从语言和文化的视角对上述和谐文 化价值因子进行分析解读, 探究其形成的历史 文化洣源, 挖掘其文化内涵, 寻找其普世价值 意义, 从而进一步促进世界文化多样性的和谐 构建。

[关键词]政治话语; 和谐内涵; 文化价值; 中 国梦
The contemporary Chinese political discourse, with Chinese cultural values as its foundation, demonstrates such discursive ideas as 'people foremost', 'harmony within diversity', 'co-existence between morals and law', 'China's Dream', and so on and so forth. This paper makes an interpretation of these harmonious cultural factors by exploring the historical origins as well as cultural connotation, trying to seek its universal values for further promotion of the harmonious construction of global cultural diversity.

Key words: political discourse; the connotation of harmony; cultural values; China' Dream.

*[作者简介] 刘和林, 长沙大学外语系副教授。研究方向: 跨文化交际与话语学研究。

[基金项目] 本文为湖南省哲学社会科学基金委托项目（第三批） “文化软实力构建中和 谐话语应用研究”（14WTC47）的部分研究成果。 
“政治话语” 是后现代主义以及社会语言学研究语言的一个切入点, 它注 重分析语言在现实权力行使中的作用。Wilson (2001) 认为, “政治话语” 有广 义和狭义之分, 从广义上讲几乎所有的话语都可以被认为具有政治性, 对话语 进行的各种分析也都具有政治性，所以话语归根到底都是政治话语。从狭义上 看政治话语是政治人物在特定政治场合所讲的话语, 这把政治领域和其他领域 （诸如工人罢工、政治人物有关政治的日常谈话等）都排除在外。近年来，国 内话语学研究者对当代中国政治话语进行了多角研究。（施旭, 2010/2014; 谢立中, 2009/2010; 田海龙、陈洁, 2012; 梅朝阳、于柏祥, 2012; 李战子、 庞超伟，2011；窦卫霖，2011；朱哓敏，2011；钱毓芳，2010；李秋杨、王国 平，2014 等等）。在此基础上，本文主要分析探讨当代中国政治话语中 “和 谐” 文化理念以及其中所蕴含的 “以人为本”、“和而不同”、“德法和谐” 等的文化因子内涵, 进而寻找其普世价值意义, 为世界文明多样性发展贡献出 中国智慧与中国力量。

\section{1. 和谐是当代中国政治话语的基本诉求}

和谐是指事物、事件协调生存与发展的一种状态。从生态学意义上说, 和 谐是指系统的组织结构处在最佳状态，能充分并能持续发挥系统的功能。和谐 理念是中国传统文化的核心理念和根本精神，“天人合一”、“和为贵”、“和 而不同”、“大同社会” 等是中国人民自古以来对人与自然，人与人、人与社 会和谐关系的理想与追求。《左传》用 “如乐之和, 无所不谐” 诗一般的语言 描绘了一幅社会和谐的图景。《易传》中也极力提倡和谐思想，并提出了 “太 和” 观念。北宋思想家张载指出: “太和所谓道, 中涵浮沉、升降、动静相感 之性, 是生氤氲相荡胜负屈伸之始。” ( 《正蒙・太和篇》) “道” 是中国传 统哲学的最高范畴。在这里, “太和” 便是道, 是最高的理想追求, 即最佳的 整体和谐状态。中国传统文化提出的这种和谐共生理想已经成为以 “和” 为核 心, 兼顾多元、和谐有序、包容开放的一套哲学或话语体系。（郑海翠、张迈 曾 2008）成了中华民族生生不息、薪火相传的力量源泉。纵观历史，可以发 现，中华话语或中国文化话语的特征在很大程度上是维护政治服务的。以《论 语》为例, 孔子穷其一生宣扬的就是 “治国安邦” 之道。“一言可以兴邦…… 一言而丧邦” (《论语・子路》) 和 “名不正则言不顺, 言不顺则事不成, 事 不成则礼乐不兴，礼乐不兴则刑罚不中，刑罚不中则民无所措手足”（同上） 都道出了儒家对政治话语的诉求（施旭，2010）。

当代中国对和谐的诉求是发自对社会主义必要性的认识和对中国近代历 史受凌辱的集体记忆。当代中国话语研究 “倡导对话语的跨学科研究, 致力于 
认识话语在当代中国社会政治变革中所起的重要作用”。(田海龙、曹青,2012) 当下, 包含和谐价值思想的和谐社会建设成了党和政府的重要政治追求。自十 六届四中全会中央政府提出构建社会主义和谐社会以来, 和谐话语的构建就成 了和谐社会构建的重要组成部分。2005 年《政府工作报告》中, 把和谐社会 建设作为政府工作的基本思路的一项重要内容, 把 “着力建设和谐社会” 作为 工作和部署上要突出抓好的一个重要方面, 从实践层面来展开分析如何进一步 构建社会主义和谐社会。十六届六中全会作出的《关于构建社会主义和谐社会 若干重大问题的决议》, 是中国共产党历史上第一次以社会建设为主题的重要 文件。第一次明确提出要把我国建设成为富强、民主、文明、和谐的社会主义 现代化国家。“十七大” 将和谐社会作为中国特色社会主义的本质属性, 表明 了我党对和谐发展所赋予的新的价值内涵（张国庆，2012）。2012 年 10 月, 党的十八大提出公平正义是中国特色社会主义的内在要求。运用法治手段推进 中国社会和谐进程。法律上的社会和谐, 其核心是公平与正义, 是对权利的承 认和保护。2015 年 10 月, 党的十八届五中全会也提出了 “社会和谐稳定” 等 的要求。习近平指出：“中华文化崇尚和谐, 中国 '和” 文化源远流长, 蕴含 着天人合一的宇宙观、协调万邦的国际观, 和而不同的社会观, 人心和善的道 德观。在 5000 多年的文明发展史中, 中华民族一直追求和传承着和平、和睦、 和谐的坚定理念。以和为贵, 与人为善, 己所不欲, 勿施于人等理念在中国代 代相传, 深深植根于中国人的精神中, 深深体会在中国人的行为上” (习近平, 2014）。当下，和谐成为了社会主义核心价值观重要内容，并通过以人为本、 和而不同、德法和谐等文化价值理念加以实现。

\section{2. 政治话语中所蕴含的和谐文化观}

当前, 中国正在致力于发展经济、保障民生、谋求突破, 正在努力构建政 治清明、经济发展、文化繁荣、生态和谐、人民安居乐业的良好政治生态话语 体系。政治话语中所蕴含的 “以人文本”、“和而不同”、“德法相容” 等文 化观成为了党和政府治国理政的重要方略。

\section{1 “以人为本” 的社会观}

人是社会的一部分, 人作为社会存在的事物相互交往而构成社会。在中华 文明 5000 年历史发展长河中, 民本思想始终贯穿其中。早在夏商时期, 就有 “民惟邦本，本固邦宁” (《尚书・五子之歌》) 的说法。孟子曰: “民为贵， 社稷次之, 君为轻”（《孟子・尽心下》）（朱学勤 2006）。清代万斯大论 述到 “圣人之治天下，利民之事，丝发必兴；厉民之事，毫末必去。”。（习 近平，2015）当代政治话语中 “民本” 或 “人本” 思想也随处可见。习近平将 《晏子春秋》中 “意莫高于爱民, 行莫厚于乐民” 演绎或发展为 “德莫高于爱 民，行莫贱于害民”（习近平，2015）的治国理念。毛泽东 “人民只有人民， 才是创造历史的真正动力”; 邓小平“先富后富论” 中“让一部分人先富起来, 
先富带动后富, 逐步走向共同富裕。如果富人越来越富、穷人越来越穷、势必 会造成两级分化，不利于社会的稳定与和谐发展” ; “三个代表” 中 “代表最 广大人民的根本利益” ; 等等。这些共同体现出以人为本的和谐价值理念。

例 1：2012 年新一届中央政治局常委与中外记者见面会上，中共中央总书 记习近平指出, 作为新一届中央领导机构, 我们深知肩负的重大责任, 这个重 大的责任包括对民族的责任、对人民的责任和对党的责任。习近平说，我们的 人民热爱生活，期盼有更好的教育、更稳定的工作、更满意的收入、更可靠 的社会保障、更高水平的医疗卫生服务、更舒适的居住条件、更优美的环境， 期盼着孩子们能成长得更好、工作得更好、生活得更好。人民对美好生活的 向往，就是我们的奋斗目标。（摘自《潇湘晨报》2012-11-16，A01 版。）

语用学特别重视语境对话语的影响及其意义的形成。在特定的语境下, 以 上话语具有如下特征。第一, 发话者通过换位思考的方式将自己置于受话人的 境地, 由此缩小了双方的语用距离; 第二, 通过预测或推理出人民对 “教育”、 “工作”、“收入”、“社会保障”、“医卫服务”、“居住条件”改善或提 高的期盼，贯彻了话语行为中 “善行原则” ; 第三，以上短短的 116 个字符中 包含了 10 个 “更” 字，预设新一届政府与时俱进的发展观以及更大的政治勇 气和政治改革决心。“更好、更稳定、更满意、更可靠、更高、更优美”与 “改 革开放只有进行时没有完成时”（习近平语）理念有异曲同工之妙，后者与日 常生活话语 “只有更好，没有最好” 的句式相近。“进行时” 和 “完成时” 是 英语的两种基本时态。在汉文化语境下它们属于外来语。在此语境下发话人通 过语用预设（pragmatic presupposition，双方共知的信息，此处指英语时态 中的 “进行时态” 和 “完成时态”) 表达一种语言或文化现象，从语效上分析， 这种语言或文化预设缩短了交际双方的语用距离, 增强了政治话语的亲密度 （intimacy）。当政治领袖人物使用大众话语来表达或传递原本较为严肃、庄 重的信息时, 其意义非同寻常——体现了一种和谐平等的价值理念, 展示了领 袖人物的亲民形象。

“人民对美好生活的向往，就是我们的奋斗目标” 是执政党在新时代对人 民郑重而务实的承诺，是 “立党为公、执政为民” 以及 “情为民所系，利为民 所谋” 科学发展观的具体落实, 是 “实现好、维护好、发展好最广大人民的根 本利益” 执政理念的具体落实，是由 “温饱” 发展至 “小康”、由 “有没有” 发展到 “好不好” 政治理想的升华。一言以蔽之，它体现出的是重民、贵民、 恤民的民本思想。当前正值中共中央关于制定国民经济和社会发展第十三个五 年规划时期, “十三五” 时期将是全面建设小康社会的决胜阶段，也是实现“两 个一百年” 奋斗目标的第一个奋斗目标的关键时期。伟大的事业离不开亿万人 民的共同奋斗，胜利的成果必将惠及全体中国人民。为此，党中央提出了 “坚 持共享发展 “的思想，即必须坚持发展为了人民、发展依靠人民、发展成果由 人民共享，作为更有效的制度安排，使全体人民在共建共享发展中有更多获得 感, 增强发展动力, 增进人民团结, 朝着共同富裕方向稳步前进。最终达到 “实 
现全体人民共同迈入小康社会” 的宏伟目标。

例 2: 因为我们是为人们服务的, 所以, 如果我们有缺点, 就不怕别人批 评指出。不管是什么人，谁向我们指出都行。只要你说得对，我们就改正。你 说的办法对人民有好处，我们就照你的办。“精兵简政”这条意见就是党外人 士李鼎铭先生提出来的; 他提得好，对人民有好处，我们就采用了。（摘自《毛 泽东选集》第三卷，北京：人民出版社，1966：905-907)

在政治话语中，人称代词 “我们”、“你们” 都是高频率用词。而人称代 词的选择往往受到交际双方的社会地位、权力关系亲疏程度的影响和限制。从 语用学角度看, “我们” 有外排 (exclusive) 和内包 (inclusive) 两种特性。 外排容易使话语对象产生受摆布之感; 而内包法旨在拉近与听话人的距离, 给 人平等参与、休戚与共的感觉（辛斌, 1997)。显然, 在 “如果我们有缺点, 就不怕别人批评指出” 中，作为话语主体的 “我们” 具有内包性，代表中国共 产党组织与代表广大人民群众的 “你们” 进行平等对话。一方面表达了“我们” 对待真理的态度。马克思主义真理观认为, 真理既是绝对的, 又是相对的。真 理的绝对性表明, 人不可能穷尽对真理的一切认识, 人的认识只能是对真理的 相对反映。人的认识的差异性、不完全性决定了人的认识是相对的、不完全或 不彻底的。对于那些认识不够完全或不够彻底的问题我们要虚心向人学习; 就 应该积极、主动地加以改进或提高。这种对真理的认知消解了 “我们” 的外排 性。另一方面， “你说的办法对人民有好处，我们就照你的办”。“你” 泛指 任何人, 采用第二人称比第三人称更具有亲切感, 如同直面交际, 倾心而谈, 营造出一种平等、和谐共处的局面, 也充分表达了中国共产党虚怀若谷的态度。 这种 “坚持批评与自我批评, 虚心接受群众意见” 的工作态度或工作作风是毛 泽东思想中 “以人为本”思想的显著特征。

中华民族的伟大复兴是一项继往开来的事业, 其复杂程度远比我们想向的 要艰难, 因此, 在实际工作中广大党员干部一方面要发挥人的主观能动性, 另 一方面也要虚心向人民群众学习, 认真听取他们的意见或建议, 对于他们提出 的好的建议或意见要虚怀若谷地接受并落实到具体工作之中。显然, 在一个十 三亿多人口的大国搞建设、谋发展, 培养和选拨德才兼备、敢于担当的党员干 部是关键。“千人之诺诺, 不如一士之谔谔” (《史记・商君列传第八》; “为 政之要, 莫先于用人” ( 《资治通鉴・魏纪五》) ; “邦之兴, 由得人也; 邦 之亡, 由失人也”（《策林・辩兴亡之由》）；（习近平，2015）等等。这些 选贤用能的政治主张, 求真务实的工作作风既包含了中国传统文化智慧也赋予 了新的时代内涵，它要求广大党员干部做到工作上 “接地气”，思想上 “扬正 气” , 行动中 “显锐气”。一句话, 要本着对党无限忠诚, 对人民高度的负责 去实现好、维护好、发展好党和政府的各项事业。 


\section{2 “和而不同” 的生态观}

和而不同的辩证思维方式是中华文化的一个古老哲学命题, 它起源于西周 史伯以及晏婴的 “和同之辩”。生活在 2500 年前的中国史学家左丘明在《左 传》中记录了齐国上大夫晏子关于 “和” 的一段话: “和如美焉, 水、火、䤈、 䤀、盐、梅, 以烹鱼肉。” “声亦如味, 一气, 二体, 三类, 四物, 五声, 六 律, 七音, 八风, 九歌, 以相成也。” “若以水济水, 谁能食之? 若琴瑟之专 壹, 谁能听之? ”太史史伯在《国语 - 郑语》中提出 “夫和实生物, 同则不 继。以他平他谓之和, 故能丰长而 物归之; 若以同裨同, 尽乃弃矣” 的和谐 思想, 指出 “和” 就是各种事物间、不同对立面相互配合、统一而达到平衡状 态，“和” 才能产生新事物。后孔子概括为 “君子和而不同，小人同而不和” （《论语・子路二三》）。钱穆（2011）提出 “以和为贵” 而行 “忠恕之道” 的君子, 应能在差异中求得和谐相处, 在保持与其他人和谐融洽关系的同时, 有自己的思想, 不会人云亦云。这样, 才能保持 “一花独放不是春, 百花齐放 春满园” 的良好文化生态。正如良好的自然生态有助于生物的多样性一样, 良 好的文化生态也能促进人类文明的互鉴和共存。

生物多样性理论强调, 丰富多样、异质性强的生态系统是最强劲的生态系 统, 多样生物相互作用、相互渗透, 才能构成一个生机勃勃的生命世界。人类 社会如同生态系统一样, 多样性是稳定性的基础。对于全球化浪潮下的各种文 化, 乐黛云坦言自己的观点: 文化 “不应该一体化。文化从来就是多元化的, 各个人类群体的生存环境不同，传统和习惯不同，文化也就不同，保存多元文 化, 也就是保持一种文化生态。文化生态和自然生态一样, 必须有不同文化相 互启发，相互促进，才可以有发展的前途。……如果我们没有不同文化的“和 而不同” , 没有 “和实生物, 同则不继” 的原则, 我们的文化也就会变成文化 沙漠”。(乐黛云, 2011) 中国文化是一种充满生态智慧的文化。“同则不继” 的观念使我们认识到一个物种如果只是种内繁殖便有退化与灭绝的危险; “和 实生物” 的思想表明适当比例的异质因子的 “和合” 有利于新事物的产生。

政治话语中蕴含的 “和而不同” 理念成为中国与世界文化交流互鉴的重要 理据。“和平共处五项原则”、“一带一路” 宏伟蓝图的规划植根于和而不同 价值思想。无论是博鳌论坛释放的 “ “一带一路” 不是独唱而是合唱” 还是英 伦三岛传递的 “所有感兴趣的国家都可以添加进入 “朋友圈” ” ，其所体现的 是习近平作为世界上最大发展中国家领袖的那种海纳百川的政治胸襟。

例 3: 中国古代思想家孟子说过：“夫物之不齐，物之情也。”不同文明 没有优劣之分, 只有特色之别。（摘自 2015 年 3 月习近平在博鳌亚洲论坛上 的讲话)

国家主席习近平在多次讲话中援引了孟子“夫物之不齐, 物之情也”之句, 强调文明相处需要和而不同的精神。正因为不同文化具有自身独特的个性, 形 成了文化多样性。因此, “在多样中相互尊重、彼此借鉴、和谐共存, 这个世 界才能丰富多彩、欣欣向荣。” 要促进不同文明不同发展模式交流对话, “要 
对话，不要排斥; 要交流，不要取代。”在竞争中取长补短，在交流互鉴中共 同发展。

和而不同文化生态观在政治话语中不仅仅体现在国与国之间的关系上,也 是党和政府处理民族关系、地区关系、阶层关系的重要理据, 由此成为凝聚民 心、筑牢党心、加固军心、实现 “中国梦” 的强大精神力量。

例 4: 实现国家统一是民族的愿望，一百年不统一，一千年也要统一的。 怎么解决这个问题，我看只有实行 “一个国家，两种制度”。世界上一系列争 端都面临着用和平方式来解决还是用非和平方式来解决的问题。总得找出个办 法来，新问题就得用新办法来解决。（摘自 1984 年 6 月 22 日 “邓小平会见香 港工商界人士谈话要点”)

“一国两制” 可谓是对 “和而不同” 文化理念的最大阐释。中国大陆和港 澳台分别以社会主义和资本主义的体制为主体，从而在社会价值观、经济发展 模式、人们的生活方式等方面存在明显不同，但二者都是炎黄子孙，都乐于实 现中华民族伟大复兴。同声相应，同气相求的精神是实现一国 “和” 的基础。 “两制” 下和谐共处、和谐发展, 充分体现了我党有容乃大的博大胸怀和杰出 的智慧。

\section{3 “德法和谐” 的伦理观}

从中国传统哲学中 “和合” 与 “生生” 的关系向度上讲, “和” 与 “生” 是同位一体的。和谐范畴在中华民族的语汇中, 可以说早在远古时代就已经出 现了，如在金文《史孔盉》中的 “史孔乍和” 即有 “和” 字。“和” 在《易经》 中有两处，如 “兑” 卦爻辞的 “和兑。吉” ; “中孚” 卦之 “九二”爻辞：“鸣 鹤在阴, 其子和之”。另外, 甲骨文则有 “衃” 字。据《说文解字》, “䎾禾” 与 “和” 基本相同, “和” 为 “相应也”, “和” 为 “调也”。故今版《辞海》 称 “䎟” 为 “和” 的异体字。而就 “和” 的语义场来说, 如和生、和谐、和善、 和爱、和气、和美、和韵、和洽、和乐、和易、何悦等等，也历史地构成了一 个生机充盈、意义丰润的能量系统。徐国超 (2010) 提出和谐稳定的社会秩序 是形成人类生活共同体的基本保障。在和谐社会构建中道德与法律起着保驾护 航的作用。德法和谐包含道德软化力量和法治刚性要求的 “和合”、“生生” 之道。

十八大以来全党全社会掀起了反腐浪潮, “法治”成为了社会主义核心价 值观。2015 年 10 月, 中共中央颁布施行新修订的《中国共产党纪律处分条例》 (以下简称《党纪处分条例》) 和《中国共产党廉洁自律准则》 (以下简称《廉 洁自律准则》) 表明中国共产党作为执政党对党的建设的长期性、复杂性、艰 巨性的正确认识。《廉洁自律准则》重在立德, 《党纪处分条例》重在立规。 两部法规亦刚亦柔, 柔中带刚, 刚中有柔, 刚柔相济。由此, 将法治的刚性与 德治的柔性有机结合。譬如, 原条例第 150 条中关于 “通奸” “包养情妇 (夫)” 
的提法在新条例中被删除, 范围扩大到 “与他人发生不正当性关系” , 让纪律 处分的面更宽更严。有些不正当性行为可能只是道德问题，不违法，以前太具 体反而容易有遗漏, 让一些人钻了空子。修改后把软约束变成硬要求。通过制 度的刚性和建设性力量，真正实现让党员干部从 “不敢腐” 到 “不能腐”、“不 想腐”。

例 5：法律与道德，历来是建立公序良俗、和谐稳定社会的两个保障。法 治与德治, 如车之双轮、乌之两翼, 一个靠国家机器的强制和威严, 一个靠人 们的内心信念和社会興论，各自起着不可替代而相辅相成、相得益彰的作用， 其目的都是要达到调节社会关系、维护社会稳定的作用，保障社会的健康和正 常运行。(摘自习近平《之江新语》，2014)

法律与道德一方面承载有共同的价值目标, 影响和规定着人们的行为方式, 另一方面两者之间也存在着一定的价值分歧, 特别是在社会转型时期, 一方有 可能超前或滞后于另一方, 形成价值的冲突 (如政治话语与日常生活话语的冲 突等）。法律与道德在运作机制与方式上也存在一定的差异, 法律体现着国家 的权力意志, 是国家强制执行的武器, 具有鲜明的时代、阶级特征等; 而作为 约定俗成的道德则是一种广泛的社会行为方式, 它更多地表征为历史的传承和 全社会共同遵守的文化特征; 法律是依靠强制手段来执行的, 并在个人行为层 面上起作用，而道德却是以感召的手段（既在人的行为又在人的思想信念层面 上）起作用; 法律是通过理性约束来维系社会公平正义的, 而道德却依靠人的 良知来区分人或事的是非曲直。由此看来, 将 “法治” 与 “德治” 相结合而形 成的 “德法和谐” 是具有中国政治哲学智慧的话语策略。

如果说西方文化崇尚法治, 中国文化则可以说崇尚礼治。追本溯源, 可以 发现, 周公 “制礼为乐” 揭开了中国礼乐文明的序幕, 儒教推广而使礼逐渐成 为维护封建社会统治的重要工具, 由此而形成的礼制就成为了中国古代社会的 治国方略, 成为了中国文化的基本人格。这种文化特征表现了中国群体之间亲 和、重礼的人际关系，也折射出中华民族和谐相处的人生价值观。“礼治”介 于德治与法治之间，常常表现为官方意识形态，可以说 “礼制” 是国家道德。 儒家主要从礼而不是法的角度来谈制度建设, 社会形成了以礼的精神、德的意 志来处理民间纠纷举措, 从社会文化层面上建构起了对有礼之德的向往和对相 争相诉的厌恶。儒家伦理主张 “礼大于法” 。孟德斯鸭在《论法的精神》中论 述道，中国立法者通过把宗教、法律、风俗、礼仪这些具有道德品质的东西混 在一起而制定出的礼制可以使百姓能平静生活、能相互信任、能彼此尊重, 可 以使每个人时刻感受到对他人的义务、感受到彼此间的相互依赖。这样文人以 之施教, 官吏以之宣传, ……当人们找到使它们获得严格遵守的方法的时候, 中国便治理得很好（何兆武、柳卸林，2011）。

例 6: “正如卢梭所说，“规章只不过是穹隆顶上的拱梁，而唯有慢慢诞 生的风尚才是最后构成那个穹隆顶上的不可动摇的拱心石”。法律当中 “最重 
要的一种”就是这种风尚, 它既不是铭刻在大理石上, 也不是铭刻在铜表上, 而是铭刻在公民们的内心里。” (摘自习近平《弘扬法治精神, 形成法治风尚》)

中华五千年文明发展中形成了礼文化特征。作为一种具有弥散性的文化模 式，礼仪 “浸润” 的方式深入到人的性情和道德意识之中，作用于人们日常生 活的一言一行、一举一动。从而使人内心接受礼的精神、外表践行礼的规范, 最终培养出文明的民众、构成稳定和谐的社会。（张自慧，2008）古今中外研 究表明, 当代中国政治话语和谐构建中文化价值重建不失为重要话语策略。包 含了古圣先贤哲学智慧的 “礼治” 等中国传统文化精髓理应成为中国现代化建 设的题中应有之义。在社会主义道德体系建设中，社会主义核心价值观、三严 三实等最具时代特征，它们共同成为了引人向上、催人奋进的道德机制，成为 了法治建设的必要补充, 成为了德法和谐的助推器。只有重新审视 “德治” 与 “法治” 的辩证统一关系，才能真正创造和谐，从而保障社会公平正义，同时 也只有德法和谐才能为 “中国梦” 的实现保驾护航。

\section{3. “中国梦” 的文化内涵}

当前中国政治哲学核心话语的内核是 “中国梦”。习近平说, “我认为, 实现中华民族伟大复兴，就是中华民族近代以来最伟大的梦想”。“中国梦” 既不同于 “美国梦” 也有别于 “欧洲梦” 。“美国梦” 是基于个人主义原则和 我行我素的对外政策而制定的。“欧洲梦” 则旨在重建中世纪那种欧洲人的集 体生活方式而诞生的。J.里夫金的《欧洲梦》认为: “欧洲梦” 正在悄悄地使 “美国梦” 黯然失色。他所谓的 “美国梦” 是指每一个人都拥有不可限制的机 遇来追求财富，而较少关注更广阔的人类福祉；而 “欧洲梦” 则是一个基于生 活质量而个人无限聚敛财富的可持续文明。

中国梦是在凝聚了 13 亿中国人民共同理想、信念和价值基础上形成的, 以实现国家富强、民族复兴、人民幸福为本质特征的，具有中国特色的社会主 义的伟大梦想或构想。理想是形成梦的基础, 信念是实现梦的保证, 价值是圆 梦的目的。“中国梦” 代表了中国亿万人民的共同心愿。寻梦、追梦、圆梦是 中国共产党领导全国各族人民艰苦奋斗的过程：“两个一百年” 是圆梦的时间 表或路线图; 党的群众路线教育实践活动及其影响是实现中国梦的思想保证; 人民群众是实现中国梦的主导力量。正如习近平所指出的, 中国梦归根到底是 中国人民的梦, 必须紧紧依靠人民来实现。“依靠人民来实现” 是 “以人为本” 价值观的理论翻版, 是 “一切为了群众, 一切依靠群众, 从群众中来、到群众 中去” 党的群众路线的发扬光大。当下 “中国梦” 及其衍生的 “亚洲梦” 连同 “欧洲梦”、“世界梦” 对 “和谐世界” 的构建将产生一定的积极影响。深信， 随着中国文化软实力的进一步增强, 中国梦价值意义将更加凸显。如果用英语 表达的话，China's Dream 比 Chinese Dream 更能表达 “中国梦” 的文化内涵。 


\section{4. 结语}

后现代与后结构批评理论指出, 文本与话语在构建社会秩序中起着重要的 作用; 文化理论是道德与政治事业的一部分（史密斯，2008）。中国文化语境 下的 “以人为本”、“和而不同”、“德法和谐” 以及 “中国梦” 等和谐价值 理念是构建当代中国政治哲学核心话语体系的重要内容。诠释、预测或解读中 国当代政治话语中和谐文化因子及其内涵意义，既要立足中国又要放眼世界， 既要尊重历史又要面向未来。由此, 才能将中国的发展优势转化为政治优势, 才能将政治话语力量转化为实现 “中国梦” 的内在驱动力, 进而为世界文化多 样性发展贡献出中国智慧与中国力量。

\section{参考文献}

窦卫霖, 2011, 中美官方话语的比较研究 [M]。上海: 上海外语教育出版社, 12-13。

（英）菲利普 - 史密斯, 2008, 文化理论：导读 [M]。张鲲译, 北京：商务出版 社, 233-234。

何兆武、柳卸林, 2011, 中国印象一一外国名人论中国文化 $[\mathrm{M}]$ 。北京：中

国人民大学 出版社, 27-37。

乐黛云, 2011 , 跟踪比较文学学科的复兴之路 [M]。 上海: 复旦大学出版社, $86-92$ 。

钱穆, 2011, 论语新解 [M]。北京：九州出版社, 323 。

人民日报评论部编著， 2015 ，习近平用典 [M]。北京：人民日报出版社， 21 ；

$16 ; 161-167$ 。

施旭, 2010, 文化话语研究 [M]。北京: 北京大学出版社, 44。

田海龙、曹青，2012，当代中国身份重建中的语言运用 [M]。天津：南开大学 出版社。

习近平，2014 年 5 月 16 日，习近平在中国国际友好大会暨中国人民对外友好

协会成立 60 周年纪念活动上的讲话 $[\mathrm{N}]$ 。人民日报（第二版）。

辛斌, 1997, 英语语篇的批评性分析诌议 [J]。四川外语学院学报, (4): 43-49。

徐国超，2010，“生态” 的意义谱系 $[\mathrm{J}]$ 。前沿，(9) : 169-173。

张国庆，和谐论概述 [Z]。wenku. baidu. com/view/5f3e9f7601f69e3. 201

$2-10-5$ 。

张自慧, 2008 , 礼文化的价值与反思 $[M]$ 。上海: 学林出版社, 79 。 
郑海翠、张迈曾, 2008, 和谐理念的多模式话语建构 [J]。外语学刊(2): 107-112。 中共中央宣传部理论局编, 2013, “中国梦” : 阐释 “中国梦” 文章选编 [C]。 北京: 学 习出版社, 160-164。

朱学勤, 2006, 四书五经 $[\mathrm{M}]$ 。上海: 上海辞书出版社, 121 。 